\title{
As Bases do Petismo
}

\section{David Samuels}

Universidade de Minnesota

\section{Resumo}

A partir dos dados do ESEB de 2002 o autor realiza um estudo das bases eleitorais do PT e de hipóteses sobre a natureza do petismo. Através de técnicas estatísticas multivariadas, são testadas relações do petismo com variáveis demográficas, socioeconômicas e variáveis relativas a questões políticas específicas. Os resultados apontam que apenas a escolaridade tem uma associação específica com o petismo, com implicações para o seu comportamento sócio-político.

Palavras-chave: Estudo Eleitoral Brasileiro; Partido dos Trabalhadores; bases partidárias; comportamento político

\begin{abstract}
Based on the results of the 2002 Brazilian Electoral Study, the author analyses the electoral bases of the Worker's Party and the factors associated with the 'petismo'. The relationships between the 'petismo' and the socioeconomic, demographic and political variables are tested using multivariate analysis. The results indicate that the only 'social category' associated with 'petismo' is level of education, and it has clear implications to their social and political behavior.
\end{abstract}

Keywords: Brazilian Electoral Study; Worker's Party; party bases; political behavior 
Em outubro de 2002, o PT tornou-se o maior partido do fragmentado Congresso brasileiro, conquistando $18,4 \%$ dos votos. A vitória de Lula na eleição presidencial realizada na mesma data levou o PT ao poder federal, após ter sido, por mais de vinte anos, o partido mais atuante da oposição. O crescimento, a transformação e a conquista do poder pelo PT numa época de predominância neoliberal e de colapso de numerosos partidos em toda a América Latina merecem atenção. O que define um petista? Que fatores estão associados ao petismo? No momento, sabemos muito pouco sobre as bases de apoio do petismo. Desde as pesquisas de Meneguello (1989) e Keck (1992) sobre os anos de formação do PT, ninguém mais investigou as bases eleitorais do partido ${ }^{1}$. Este artigo é um exame preliminar das bases do petismo, usando dados do Estudo Eleitoral Brasileiro de 2002 (ESEB).

Consideramos que os petistas diferem substancialmente dos outros brasileiros. Eles se identificam como sendo de esquerda, são mais instruídos e politicamente conscientes do que a média. Além disso, não somente acreditam que a participação do indivíduo na política pode fazer diferença, como também estão muito mais envolvidos em ações políticas e sociais do que os outros. Deste modo, eles não só abraçam, como põem em prática o objetivo declarado do PT de "movimentar as bases", ou seja, os atores que não pertencem à elite, para transformar a sociedade brasileira.

Por outro lado, vários fatores que se suporiam associados ao petismo revelam-se de pouca importância. Por exemplo, a classe socioeconômica não diferencia os petistas dos outros brasileiros e eles não defendem, em relação às políticas públicas, posições substancialmente diferentes dos demais cidadãos. Tais características sugerem que o petismo representa antes uma transformação cultural na sociedade brasileira do que uma clivagem de classe ou uma distinção baseada em posições políticas específicas.

Neste artigo, exploramos várias hipóteses sobre a natureza do petismo através da análise dos dados do Estudo Eleitoral Brasileiro mas, antes, para contextualizar a análise, descrevemos o crescimento do PT.

\footnotetext{
1 Em obra recente, analisei a moderação do PT, mas somente no nível da liderança e em termos do partido como instituição. Ver Samuels (2004a).
} 


\section{A evolução do apoio ao PT}

O Partido dos Trabalhadores foi fundado em 1980, logo depois que o regime militar permitiu a formação de partidos políticos independentes desde o golpe de 1964. Na sua fundação, o PT uniu militantes políticos de esquerda, militantes das comunidades de base da Igreja Católica que seguiam a "Teologia da Libertação", intelectuais moderados e líderes de sindicatos e de movimentos sociais. A heterogeneidade e sua criação de baixo para cima o tornaram único na história dos partidos no Brasil e, talvez, na América Latina (MENEGUELLO, 1989; KECK, 1992). Embora o PT jamais se tenha deliberadamente identificado com um tipo específico de esquerdismo, ele "sempre se definiu como socialista" (KECK, 1992, p. 246) e, historicamente, defendeu muitas posições políticas radicais.

Até 2002, o PT atuou como partido de oposição a todos os governos federais. A cada eleição legislativa, o partido ampliava sua representação no Congresso. A Tabela 1 mostra a proporção de votos do PT nas eleições legislativas, revelando seu lento, mas constante crescimento desde 1982.

Tabela 1

Apoio ao PT em eleições legislativas federais (\% de votos)

\begin{tabular}{|c|c|}
\hline 1982 & 3.5 \\
\hline 1986 & 6.9 \\
\hline 1990 & 10.2 \\
\hline 1994 & 12.8 \\
\hline 1998 & 13.2 \\
\hline 2002 & 18.4 \\
\hline
\end{tabular}

Fontes: Dados Eleitorais do Brasil (Edição Eletrônica), 1982-2002. www.iuperj.br/deb/port/

A evolução das preferências por partidos no Brasil espelha esse crescimento do apoio eleitoral. O Gráfico 1 mostra a evolução das preferências pelos seis principais partidos do país desde 1989. As pesquisas que forneceram as informações do Gráfico 1 pediram uma resposta espontânea para a questão: "Qual é seu partido preferido?" 


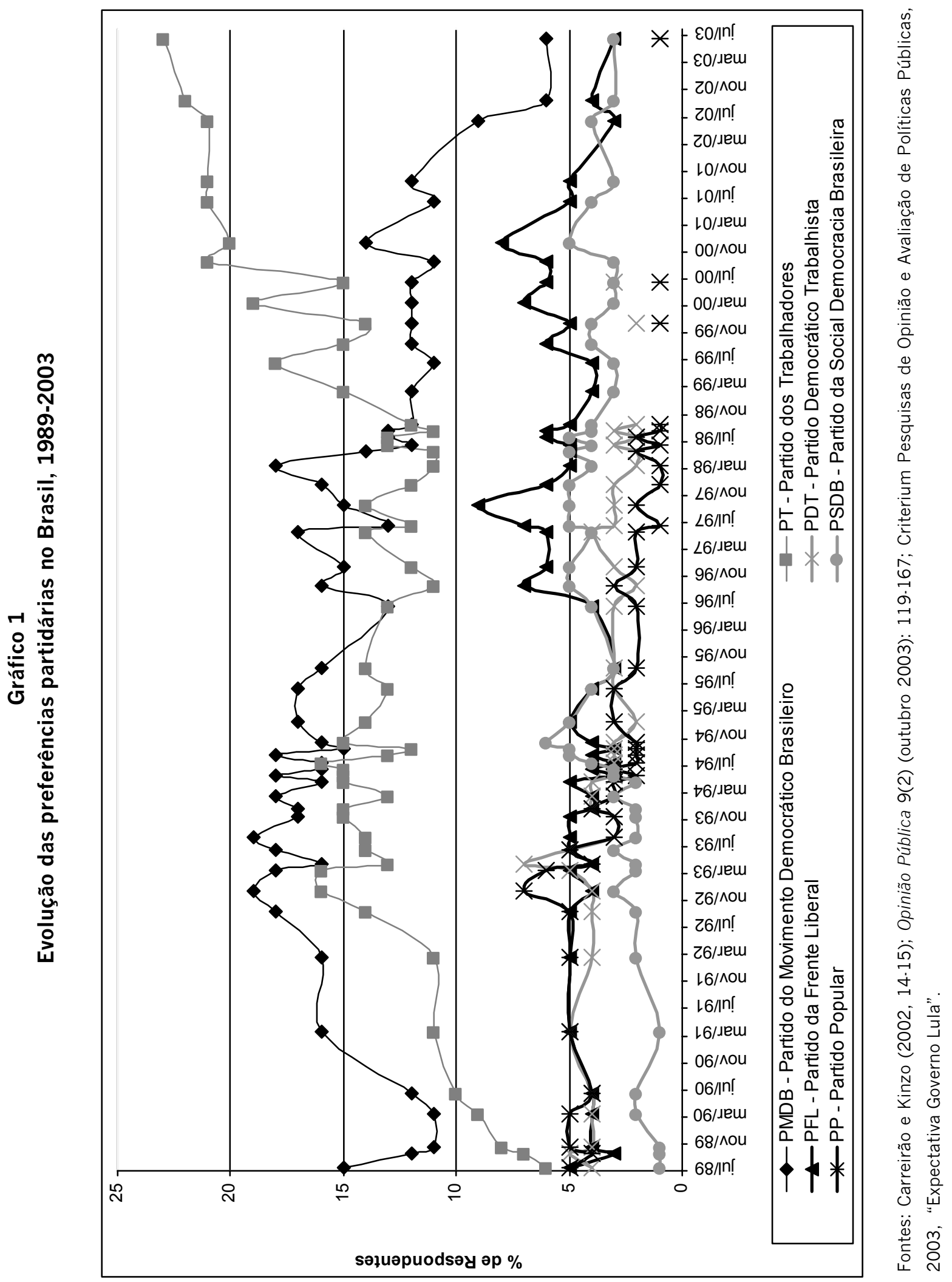


O Gráfico 1 revela que o apoio ao PT cresceu de 6\% dos eleitores em 1989 para 23\% em 2003 e que o apoio ao PMDB, o partido que, nos anos oitenta, herdou o poder do regime militar, declinou de $15 \%$ para $6 \%$ durante o mesmo período. Além disso, nenhum outro partido conquistou uma base considerável de adeptos.

O ESEB realizado após a eleição de 2002 pesquisou também em que medida há identificação com partidos no Brasil. Embora tenha usado uma pergunta levemente distinta (da utilizada nas pesquisas do Gráfico 1) para avaliar o partidarismo, a porcentagem dos que se identificam com o PT é praticamente a mesma para o ESEB e para os dados de 2003.

Em vez de fazer uma única questão aberta, o ESEB perguntou primeiro aos respondentes: "Existe algum partido político que represente a maneira que o Sr. pensa?". Se a resposta fosse positiva, o survey perguntava então: "Qual partido?" Este último formato é o padrão utilizado em estudos de eleições nacionais em todo o mundo. A Tabela 2 mostra a divisão do partidarismo no Brasil em 2002, usando os dados do ESEB, como proporção de todos os eleitores e como proporção daqueles que expressam uma preferência partidária.

Tabela 2

Identificação partidária por partido (IDP), Brasil 2002 (ESEB)

\begin{tabular}{|c|c|c|c|}
\hline Partido & \% IDP em população & \% de IDP válida & \% voto, 2002 \\
\hline PT & 23.1 & 65.6 & 18.4 \\
PMDB & 3.8 & 10.9 & 13.4 \\
PSDB & 3.7 & 10.5 & 14.3 \\
PFL & 2.2 & 6.3 & 13.4 \\
PDT & 0.5 & 1.5 & 5.1 \\
PTB & 0.5 & 1.3 & 4.6 \\
Outros (11 partidos) & 1.2 & 3.8 & 30.8 \\
\hline TOTAL & $\mathbf{3 5 . 0}$ & $\mathbf{1 0 0 . 0}$ & $\mathbf{1 0 0 . 0}$ \\
& & & \\
\hline
\end{tabular}

Fontes: ESEB 2002, TSE 2002. 
Com base na Tabela e de acordo com várias pesquisas diferentes, podemos resumir a situação em 2003 apontando que: cerca de dois terços dos brasileiros não expressam preferência partidária, cerca de um em cada quatro brasileiros expressa preferência partidária pelo PT e um em cada dez expressa preferência por um dos outros partidos. A distribuição do partidarismo é, portanto, altamente enviesada. Por exemplo, PFL, PMDB, PTB e PSDB, quatro dos maiores partidos do centro e da direita do espectro político brasileiro, obtiveram 45,7\% dos votos nas eleições legislativas, mas somente $10,2 \%$ dos brasileiros manifestam uma preferência por algum desses partidos. Deste modo, embora existam vários partidos eleitoralmente fortes no país, a identificação partidária é relativamente fraca para todos as organizações, exceto para o PT.

\section{Uma explicação para as bases do petismo}

O apoio ao PT aumentou consistentemente desde o retorno à democracia no país. Quais são as bases deste apoio? Sejamos mais específicos sobre a variável dependente que vamos examinar. Medimos o apoio ao PT como identificação partidária com o partido. Neste caso, o respondente do ESEB primeiro declara que se identifica com um partido e em seguida declara qual o partido. Testamos estatisticamente várias hipóteses para descobrir as bases de apoio do PT assim definidas, sendo que algumas dessas hipóteses são bem conhecidas na literatura internacional sobre comportamento eleitoral e outras são específicas ao contexto brasileiro.

Nossa primeira hipótese sugere que o petismo está associado a certas classes trabalhadoras. O ESEB pediu aos respondentes que informassem sua situação de emprego, bem como seu trabalho específico. A partir das respostas dos indivíduos foi gerada a seguinte classificação para os setores de trabalho: Agricultura, Pequena burguesia, Dona de casa, Setor autônomo informal, Profissões liberais, Militar ou Policial, Mão-de-obra especializada, Mão-de-obra nãoespecializada, Aposentado, Estudante e Desempregado. Esta classificação baseia-se no estudo clássico de Erikson e Goldthorpe (1992) e classificações similares foram utilizadas na literatura internacional sobre comportamento eleitoral. Estas categorias "diferenciam posições dentro dos mercados de trabalho e unidades de produção [...] em termos das relações de emprego que acarretam" (ERIKSON e GOLDTHORPE, 1992, p. 37). As categorias não levam em conta simplesmente a divisão básica de empregadores, autônomos e empregados, mas oferece distinções um pouco mais refinadas. 
No fim das contas, essas categorias são necessariamente imperfeitas e admitimos que outra pessoa poderia gerar classificações levemente distintas. Ademais, em última instância, a hipótese que fazemos a partir dessas classificações é imprecisa, dado que não temos expectativas teóricas claras em relação a várias das categorias. Não obstante, procuramos aproximação com as pesquisas existentes para testar uma hipótese importante que relaciona setor de emprego com partidarismo. Isto é talvez o melhor que podemos fazer com os dados disponíveis. Assim, tendo em vista os relatos históricos do desenvolvimento do PT (MENEGUELLO, 1989; KECK, 1992), lançamos a hipótese de que os setores de "mão-de-obra especializada" deveriam estar positivamente associados com o petismo, enquanto os setores "militar/policial" e "pequena burguesia" deveriam apresentar uma associação negativa. Com relação às demais categorias, não temos fortes expectativas a priori.

A segunda hipótese explora se uma avaliação retrospectiva do governo Fernando Henrique Cardoso está relacionada com o petismo. Desde sua fundação e até conquistar o poder federal, o PT foi um adversário ativo de todos os governos brasileiros. Os observadores sabem que a avaliação do Plano Real foi um forte determinante do voto nas eleições de 1994 e 1998, vencidas por FHC (p. ex., BAKER, 2002; CARREIRÃO, 2002). Diante disto, é esperado que o petismo seja negativamente associado a uma avaliação retrospectiva do governo FHC.

A terceira hipótese associa avaliações afetivas sobre Lula feitas pelos cidadãos com o fato de serem ou não petistas. Em todo o mundo, as avaliações que os eleitores fazem dos líderes políticos desempenham um papel importante na formação do partidarismo. Talvez de modo óbvio, espera-se que seja mais provável que os eleitores que pensam positivamente a respeito de Lula sejam petistas e, de forma mais significativa, através de técnicas multivariadas, poderemos revelar o peso relativo do personalismo comparado a outras variáveis.

O auto-posicionamento ideológico dos eleitores também deveria afetar sua identificação partidária. Singer (1999) apresentou argumento similar de que o posicionamento dos eleitores numa escala esquerda-direita delineia as eleições presidenciais brasileiras. Entretanto, Almeida e Young (2002) criticaram fortemente as bases metodológicas de Singer. Tendemos a concordar com estes últimos, mas a hipótese que vincula a auto-identificação de esquerda e petismo merece ser examinada. Assim, esta variável foi incluída na análise e teve seu impacto relativo medido. Também comentamos o que acontece com os resultados quando excluímos o "auto-posicionamento ideológico", dado o potencial em que essa variável está correlacionada com outras. 
Os estudiosos também associam com freqüência o pertencimento a certas categorias ou grupos sociais ao comportamento eleitoral ou ao partidarismo. Por exemplo, a teoria de Lipset e Rokkan (1967) sustenta que as clivagens históricas que dividem as sociedades tendem a determinar a formação dos sistemas partidários e, assim, o comportamento dos eleitores. Como afirmaram outros estudiosos (p. ex., MAINWARING, 1999; MAINWARING, MENEGUELLO E POWER, 2000), o Brasil não apresenta tais clivagens e o sistema partidário contemporâneo também não possui continuidades fortes com períodos anteriores de competição democrática, ao contrário dos sistemas partidários do Chile, Argentina e Uruguai, por exemplo.

Apesar dessas assertivas, não devemos supor que interesses sociais específicos não estejam relacionados ao petismo. Por exemplo, os militantes das comunidades de base católicas desempenharam um papel chave na formação do PT (KECK, 1992, p. 97-98). Em contraste, embora o PT conte com alguns líderes cristãos evangélicos importantes (como Benedita da Silva, ex-Ministra do Governo Lula), a maioria dos líderes evangélicos aliou-se a outros partidos, em particular ao Partido Liberal, que estabeleceu um terreno de avanço no Congresso para abrigar pastores transformados em políticos. Consideradas as diferenças entre evangélicos e católicos, podemos supor que é menos provável que os primeiros identifiquem-se com o PT, ao contrário dos católicos.

Outras características também podem ser importantes. A raça, por exemplo, certamente molda a vida dos brasileiros. Almeida (1998, p. 54) sugeriu que os nãobrancos tinham maior probabilidade de apoiar Lula e o PT devido à oposição que sempre manifestaram às tradicionais hierarquias sociais brasileiras. Em termos de gênero, por sua vez, a afinidade política do PT com os movimentos sociais, inclusive de mulheres, gera a hipótese de que as mulheres sejam mais petistas do que os homens (MACAULAY, 2003). As diferenças de geração também podem estar associadas ao petismo, na medida em que as pesquisas de opinião sempre revelaram que os eleitores mais velhos são avessos a apoiar o partido.

Por fim, a classe social pode ser importante. Lula, um migrante do nordeste para o sudeste do país, com relativamente pouca educação formal, emergiu das classes populares. De um lado, podemos lançar a hipótese de que os eleitores de classe baixa têm maior probabilidade de serem petistas. Por outro lado, o PT transformou-se num partido das classes médias organizadas, que estão mais bem integradas na sociedade brasileira do que as massas excluídas, dada especialmente a associação do partido com o sindicalismo do setor formal e o predomínio de profissionais de classe média entre os eleitos pelo PT (RODRIGUES, 2002). Desse modo, podemos também lançar a hipótese de que é mais provável que eleitores de 
classe média sejam petistas. A variável renda familiar foi utilizada para testar estas hipóteses contraditórias, bem como a potencial conexão entre dois outros indicadores de status social - escolaridade e conhecimento político. Se o PT tornouse, de fato, um partido mais de classe média, então, esperamos que essas duas variáveis estejam positivamente associadas ao petismo.

Voltemo-nos agora para outras variáveis adicionais que os observadores do Brasil poderiam supor associadas ao petismo. O crescimento do PT tem sido há muito associado às "novas" formas de ação social, do novo sindicalismo aos novos movimentos sociais (KECK, 1992), e com a promoção de formas de participação democrática que diferem dos modos tradicionais brasileiros (BAIOCCHI, 2003). Embora os atrativos eleitorais do PT sejam heterogêneos, Nylen afirma que seu atrativo contemporâneo segue três linhas básicas: um esforço para reduzir as escandalosas desigualdades sociais, um foco no bom governo e na prática ética e um desejo de "transformar a cultura política paternalista do Brasil através da participação política das não-elites e seu empoderamento" (NYLEN, 2000, p. 141).

Podemos traduzir a caracterização feita por Nylen da atração do PT em hipóteses derivadas das questões do ESEB. Em primeiro lugar, em termos do esforço para diminuir as desigualdades sociais e econômicas, embora a pesquisa não faça perguntas diretas sobre isto, apresenta uma série de questões sobre apoio à intervenção e regulamentação do governo na economia e nacionalismo econômico. A visão convencional suporia que o petismo estaria correlacionado de modo positivo a esses sentimentos.

Em segundo lugar, em termos do foco do partido no bom governo e na prática ética, nossa hipótese é a de que os partidários do PT apresentam um grau menor de apoio às práticas políticas clientelistas do que os outros brasileiros e que também mostram um nível menor de apoio ao conceito do 'rouba-mas-faz'. Ambos os conceitos são medidos mediante a construção de índices no ESEB.

Por fim, temos várias maneiras de tratar a questão do desejo do PT de transformar a cultura política brasileira. A hipótese aqui é que os brasileiros que apóiam a liberdade de expressão política e que apresentam visões menos hierárquicas da sociedade têm maior probabilidade de serem petistas, assim como os brasileiros social e politicamente engajados. Finalmente, o petismo deveria estar associado a uma crença maior na eficácia da participação política, ou seja, na probabilidade de que esta participação traga mudanças. Ao contrário, os outros brasileiros seriam mais céticos em relação à capacidade da participação política de provocar mudanças. 


\section{Análise}

Para revelar as relações estatísticas que sustentam o petismo, devem-se utilizar técnicas estatísticas multivariadas, a fim de avaliar adequadamente quais variáveis são relativamente mais ou menos importantes. Dada a natureza da questão do ESEB sobre partidarismo, a identificação com o PT não é uma escolha dicotômica (ou seja, "Eu me identifico com o PT" ou "Eu não me identifico com o PT"). Como vimos, o ESEB aplica duas questões para avaliar a identificação partidária e a análise estatística desenvolvida aqui explora os correlatos das respostas à segunda questão("Qual partido?"). Tais questões geram um conjunto de categorias, em oposição a uma resposta binária ("sim/não") ou a uma resposta ordinal, tal como uma classificação entre zero e cem em algum tipo de escala.

O método estatístico apropriado para explorar questões com respostas categóricas deve permitir categorias múltiplas sobre a variável dependente. Utilizamos o método da regressão logit multinomial com erros-padrão robustos. Para os correlatos de petismo, o modelo de regressão inclui categorias para os quatro partidos com as maiores bases partidárias, tal como aparecem na Tabela 2: PT, PSDB, PMDB e PFL, bem como categorias para identificação partidária com "Outro" e "Nenhuma", na qual "nenhuma identificação partidária" serve como categoria de referência. Apenas para este modelo, os valores missing ${ }^{2}$ foram substituídos pela média. A Tabela 3 apresenta os resultados para o petismo 3 :

\footnotetext{
${ }^{2}$ A imputação através do programa AMELIA (HONAKER et al, 2000) revelou-se impraticável para este modelo: o programa não gerava valores imputados quando as variáveis "categoria de emprego" eram incluídas. Ver nota 3 sobre AMELIA.

3 Para um exame do partidarismo em geral, ver SAMUELS, 2004b.
} 
Tabela 3

Resultado Logit Multinomial, Bases do Petismo

\begin{tabular}{|c|c|}
\hline Variável independente & Coeficiente (Erro Padrão) \\
\hline Trabalhador rural & $-.654(.421)$ \\
\hline Pequeno burguês & $-.309(.406)$ \\
\hline Dona de casa & $-.012(.279)$ \\
\hline Setor informal & $.088(.380)$ \\
\hline Profissões liberais & $-.352(.308)$ \\
\hline Militar/Policial & $-.492(.669)$ \\
\hline Mão-de-obra especializada & $.055(.310)$ \\
\hline Mão-de-obra não especializada & $.076(.231)$ \\
\hline Aposentado & $.145(.318)$ \\
\hline Estudante & $.084(.303)$ \\
\hline Desempregado & $-.025(.280)$ \\
\hline Avaliação do governo FHC & $-.142(.040)^{* * *}$ \\
\hline Opinião sobre Lula & $.375(.043)^{\star \star *}$ \\
\hline Ideologia esquerda-direita & $-.091(.021)^{\star \star *}$ \\
\hline Católico & $.086(.199)$ \\
\hline Evangélico & $.090(.237)$ \\
\hline Não-branco & $.129(.134)$ \\
\hline Mulheres & $-.129(.147)$ \\
\hline Idade & $-.007(.006)$ \\
\hline Renda familiar & $-.001(.001)$ \\
\hline Escolaridade & $.038(.018)^{*}$ \\
\hline Conhecimento político & $.129(.037)^{\star \star \star}$ \\
\hline Intervenção do governo & $.013(.011)$ \\
\hline Regulamentação do governo & $-.009(.015)$ \\
\hline Nacionalismo econômico & $.009(.014)$ \\
\hline Apoio ao clientelismo & $-.021(.013)$ \\
\hline Apoio ao rouba-mas-faz & $-.011(.008)$ \\
\hline Liberdade de expressão & $-.023(.017)$ \\
\hline Valores hierárquicos & $.020(.023)$ \\
\hline Participação eleitoral & $.201(.051)^{\star * *}$ \\
\hline Participação não-eleitoral & $.178(.045)^{\star * *}$ \\
\hline Eficácia da participação & $.137(.064)^{*}$ \\
\hline Constante & $-5.142(.888)^{\star * \star}$ \\
\hline
\end{tabular}


Cabe destacar as variáveis que não são estatisticamente significantes. Em primeiro lugar, os resultados mostram que a hipótese que vincula categoria de emprego com petismo não se sustenta de modo algum. Dada a história do PT, poderíamos, por exemplo, supor que a pequena burguesia e os militares apresentariam menor probabilidade de serem petistas e que seria mais provável que os trabalhadores especializados o fossem. Outras hipóteses são possíveis, mas sua enumeração é inútil, uma vez que nenhuma categoria está relacionada ao petismo ${ }^{4}$. Também a renda familiar não apresenta relação com o petismo. Juntos, os resultados sobre renda e classificação de emprego indicam que a classe socioeconômica não está diretamente relacionada ao petismo.

É possível notar também, talvez com alguma surpresa, que os resultados de todas as outras "categorias sociais" - raça, gênero, religião e idade - não apresentam relação com o petismo. Assim, embora tenhamos sugerido que a filiação religiosa poderia estar relacionada ao petismo, não é verdade que os católicos sejam mais petistas e que os evangélicos menos. A variável raça também não mostra relação significativa, ao contrário do que afirma Almeida (1994).

Podemos também ver que, embora Nylen (2000) possa estar correto ao identificar as principais linhas de atração do PT, poucos desses atrativos ressoam suficientemente junto aos cidadãos brasileiros para que sejam associados ao petismo. Em primeiro lugar, o atrativo do PT de reduzir a desigualdade socioeconômica não se reflete nos resultados de regressão (embora isso possa se dever ao formato da questão, que não foi formulada especificamente para testar este tema). De qualquer modo, o desejo de maior influência do governo na economia e maior regulamentação desta, bem como o apoio ao nacionalismo econômico não estão associados ao petismo (é importante ressaltar que essas três variáveis só se correlacionam com a identificação esquerda-direita num nível .06 ou mais baixo). Além disso, os brasileiros que se opõem às práticas clientelistas e ao rouba-mas-faz não apresentam maior probabilidade de serem petistas. Por fim, e de novo com alguma surpresa, os brasileiros que apóiam a liberdade de expressão política e que têm idéias menos hierárquicas da sociedade também não mostram maior probabilidade de serem petistas ${ }^{5}$.

\footnotetext{
4 Emprego administrativo foi usado como categoria de referência, porque membros dessa categoria tinham uma opinião a respeito de Lula que estava mais próxima da média para todos os brasileiros.

5 Em outro trabalho (SAMUELS, 2004) descobrimos que juventude e oposição ao clientelismo e à corrupção também estavam associados ao petismo. Esses resultados ocorreram porque foi utilizado um modelo de regressão diferente, bem como um procedimento estatístico diferente. No presente trabalho, devido ao desejo de testar a relação entre classificação de emprego e petismo, tivemos de usar o método de substituição pela média, em vez de imputação múltipla para os dados missing, porque não poderíamos imputar estes dados quando as variáveis de classificação de emprego fossem incluídas no modelo. Em Samuels (2004), a relação entre classificações de emprego e petismo não foi explorada e, assim, confiamos totalmente na imputação múltipla usando o programa AMELIA. Uma vez que a
} 
Voltemo-nos agora para as variáveis estatisticamente significativas. Podemos ver que as bases do petismo parecem estar nos eleitores que têm opinião negativa sobre o governo $\mathrm{FHC}$, uma opinião positiva sobre Lula, uma autoidentificação de esquerda, um maior grau de escolaridade e conhecimento político, uma crença na eficácia da participação política e um desejo de agir com base em suas crenças, envolvendo-se muito em atividades políticas eleitorais e não-eleitorais. Ou seja, os fatores fundamentais que definem quem é e quem não é petista parecem estar relacionados com o terceiro aspecto de atração do PT, entre os brasileiros que exibem um desejo de "transformar a cultura paternalista do Brasil via participação política das não-elites e seu empoderamento".

Com base nesses resultados, o próximo passo é descobrir a importância relativa de cada uma das variáveis significantes. No modelo de regressão seguinte são incluídas somente aquelas variáveis que foram estatisticamente relevantes ao nível de .05 ou mais na Tabela 3: avaliação retrospectiva do governo $\mathrm{FHC}$, opinião sobre Lula, posicionamento esquerda-direita, eficácia do voto, conhecimento político, participação política, participação não-política e escolaridade. Para este modelo, utilizamos o pacote de software AMELIA para imputar os missing values nos dados (HONAKER et al, 2000), o que oferece resultados melhores (estatisticamente falando) do que o método de substituição pela média6.

Os coeficientes logit são difíceis de interpretar porque não representam o efeito linear de acrescentar "outra unidade" da variável independente à variável dependente. Uma vez que já sabemos que todas as variáveis no modelo abaixo são estatisticamente significantes e estamos interessados em descobrir seu impacto relativo, em vez de apresentar resultados de regressão, como na Tabela 3, utilizaremos um procedimento que permite comparações fáceis do impacto relativo de cada variável. Isto significa usar o módulo do software CLARIFY para o pacote estatístico STATA 8.0 (KING et al, 2000; TOMZ et al, 2003)7. O CLARIFY toma os coeficientes de regressão em modelos logísticos e calcula a probabilidade predita de obter qualquer dos resultados na variável dependente dado um conjunto de parâmetros para as variáveis independentes. Assim, o modelo de regressão inicial,

\footnotetext{
substituição pela média resulta geralmente apenas em erro do Tipo II (encontrar uma relação onde não existe nenhuma), os resultados apresentados aqui não são problemáticos em termos de qualquer superestimação de relações estatísticas, porque não foi encontrada nenhuma relação entre categorias de emprego e petismo e todas as outras variáveis que eram significativas aqui também eram no outro trabalho.

6 Ver King et al (2001) para uma discussão sobre porque o AMELIA é superior a outros métodos que tratam de dados missing, tais como listwise deletion e substituição pela média (os erros-padrão que o AMELIA produz por imputação múltipla têm menor probabilidade de resultar em erro de Tipo II).

7 O CLARIFY não pode ser rodado através do SPSS. É claro que se pode computar probabilidades preditas à mão, mas o procedimento pode se tornar muito árduo. Ver King et al (2000) sobre o uso do CLARIFY.
} 
por exemplo, poderia predizer que a probabilidade de um brasileiro ser petista é .20, significando que o modelo prediz que um em cada cinco brasileiros é petista ${ }^{8}$.

$\mathrm{Na}$ Tabela 4 apresentamos as mudanças em probabilidades preditas para as variáveis independentes que eram estatisticamente relevantes no modelo da Tabela 3. Inicialmente, todas as variáveis independentes foram colocadas em seu valor médio. A primeira linha da Tabela apresenta a linha-base da probabilidade predita de um brasileiro ser petista dados estes valores. Em essência, esta é a probabilidade de que um brasileiro com disposição "média" em relação a todas as variáveis do modelo seja petista. Os valores nas células representam então a mudança na probabilidade predita de ser um petista que resulta da mudança de valor apenas daquela determinada variável, independente de sua média para seu máximo, enquanto todas as outras são mantidas na média. Os valores nas células podem, portanto, variar de $-1.00 \mathrm{a}+1.00$, e podem ser lidos como porcentagens.

\section{Tabela 4}

\section{Mudanças em Probabilidades Preditas do Petismo}

\begin{tabular}{|l|c|}
\hline Linha-base & Petismo \\
\hline Opinião sobre Lula & +.649 \\
\hline Posição esquerda-direita & -.159 \\
\hline Participação não-eleitoral & +.146 \\
\hline Escolaridade & +.083 \\
\hline Conhecimento político & +.081 \\
\hline Avaliação retrospectiva & -.079 \\
\hline Eficácia do voto & +.066 \\
\hline Participação eleitoral & +.055 \\
\hline
\end{tabular}

\footnotetext{
${ }^{8}$ O CLARIFY não somente prediz probabilidades de cada resultado, levando em conta os valores que os dados fornecem, como também permite que o pesquisador calcule o impacto de mudar os valores de variáveis independentes sobre as probabilidades preditas de obter tal resultado. Por exemplo: suponhamos que queremos saber o impacto da escolaridade sobre a probabilidade de um brasileiro ser petista. Em primeiro lugar, estabeleceríamos todas as variáveis em seu valor médio e obteríamos uma predição de linha-base. Então mandaríamos o CLARIFY mudar apenas o valor da escolaridade de seu valor médio para o máximo e depois pedir que calculasse a mudança na probabilidade de ser um petista que resulta disso. Ao fazer isto para todas as variáveis, ou pelo menos para as estatisticamente significativas, podemos avaliar o impacto relativo de cada uma delas.
} 
A variável mais importante que surge em termos do impacto sobre ser petista é a opinião sobre Lula. O resultado aqui mostrado indica que a predição aumenta quase $65 \%$ para um brasileiro que dá nota 10 a Lula numa escala de 0 a 10, em comparação com quem dá nota 5 na mesma escala. Este resultado não surpreende, tendo em vista nossa expectativa prévia de que quem gosta de Lula provavelmente seja petista. A segunda variável mais importante é o posicionamento ideológico esquerda-direita. Sobre esta, com base no debate entre estudiosos da política brasileira sobre a influência do personalismo e da ideologia no comportamento eleitoral, precisamos comparar o impacto relativo destas duas variáveis antes de continuar a discutir as outras variáveis estatisticamente significativas.

O modo de fazer essa comparação dá-se, primeiro, fixando todas as variáveis em seus valores médios e obtendo a predição da linha-base. Depois, obtemos a probabilidade de ser petista quando todas as variáveis da Tabela 4 são colocadas em seus valores de "maior probabilidade de ser petista". Ou seja, podemos mandar o CLARIFY fixar "avaliação retrospectiva" em seu valor mínimo (isto é, anti-FHC), a "opinião sobre Lula" em seu valor máximo, esquerdismo em seu valor mínimo (isto é "mais esquerdista") para todos os brasileiros e depois pedir ao programa para predizer a probabilidade de um brasileiro com aquelas características ser petista. Em seguida, podemos mudar os valores de qualquer das variáveis a fim de medir o impacto relativo de mudar o valor de uma determinada variável sobre a predição. A Tabela 5 apresenta vários cenários.

Tabela 5

Probabilidades preditas simuladas de petismo

\begin{tabular}{|l|c|}
\hline Cenários simulados & Probabilidade Predita \\
\hline Todas variáveis em valor médio (linha-base) & .138 \\
\hline $\begin{array}{l}\text { Opinião sobre Lula e posicionamento esquerda-direita na } \\
\text { média, todas as outras variáveis no cenário mais provável }\end{array}$ & .785 \\
\hline $\begin{array}{l}\text { Opinião sobre Lula na média, e todas as outras no cenário } \\
\text { mais provável }\end{array}$ & .892 \\
\hline $\begin{array}{l}\text { Posicionamento esquerda-direita na média, e todas as outras } \\
\text { no cenário mais provável }\end{array}$ & .989 \\
\hline Todas variáveis no cenário mais provável & .996 \\
\hline
\end{tabular}


A probabilidade básica de que um brasileiro "médio" seja petista é de cerca de $13,8 \%$. A última linha apresenta a probabilidade predita quando todas as variáveis são fixadas em seus valores de "maior probabilidade de ser petista". A simulação possui claramente fortes poderes de predição: usando apenas essas variáveis, podemos predizer um partidário do PT quase $100 \%$ das vezes. Ou seja, no mundo real, um brasileiro com essas características será quase sempre petista (lembro o leitor que as outras categorias possíveis que a regressão poderia predizer eram pefelista, peemedebista, peessedebista, outro partido e sem identificação partidária).

Von Mettenheim (1995), Carreirão (2002), Almeida (2004) e outros pesquisadores julgam que o personalismo é talvez a variável mais importante para explicar as eleições brasileiras. Ao contrário, Singer (1999) sugeriu que as propensões ideológicas são mais decisivas. Qual é a importância relativa para o petismo do auto-posicionamento esquerda-direita e das simpatias personalistas por Lula? A questão da importância da ideologia parece particularmente relevante no caso do petismo e as simulações nos permitem avaliar estes argumentos. Se colocamos a variável "opinião sobre Lula" em sua média e a posição esquerdadireita também na média, mas fixamos todas as outras variáveis significativas em seus valores de "maior probabilidade de ser petista", vemos na segunda linha da Tabela 5 que a predição de petismo é de cerca de $79 \%$. Isto indica que se supomos uma indiferença em relação a Lula e nenhuma posição ideológica em particular, um brasileiro com todas as outras características prováveis de petista ainda mostra probabilidade de se identificar como petista $79 \%$ das vezes.

A diferença entre a segunda e a última simulação revela o quanto resta a ser explicado usando-se personalismo e ideologia e mantendo-se o resto igual. Para comparar o impacto relativo destas duas variáveis, simularemos a adição de cada uma separadamente. A terceira simulação revela o aumento na predição quando nosso brasileiro hipotético continua indiferente a Lula, mas é um esquerdista convicto. A predição de petismo aumenta de $79 \%$ para cerca de $89 \%$, o que significa que nesse cenário, quase nove em cada dez brasileiros identificar-se-ão como petistas. A simulação seguinte faz o oposto, dando ao nosso brasileiro imaginário valor médio em ideologia e a máxima avaliação de Lula. A predição aqui é de quase $99 \%$, muito melhor do que a simulação em que o esquerdismo foi maximizado e a ligação personalista com Lula foi mantida na média.

Os cenários revelam que a opinião sobre Lula tem muito mais influência sobre o petismo de um brasileiro do que sua identificação como esquerdista ou não. O personalismo tem um impacto maior do que a ideologia em termos das bases do petismo. Não obstante, este resultado precisa ser colocado em perspectiva relativa aos outros partidos brasileiros. Observe-se que podemos predizer se alguém é petista quase $80 \%$ das vezes, mesmo sem a resposta do 
entrevistado sobre Lula ou seu posicionamento ideológico! Em outro trabalho, mostramos que não é possível predizer partidarismo para nenhum dos outros grandes partidos do país com tanta precisão quanto é possível para o PT e que o personalismo desempenha um papel muito mais importante em relação aos outros partidos do que ao PT. Desse modo, embora o personalismo desempenhe realmente um papel importante na formação do petismo, este papel é muito mais limitado do que para os outros partidos. Além disso, o auto-posicionamento esquerda-direita mostrou-se irrelevante para o partidarismo no que tange a partidos como PFL, PMDB e PSDB, significando sua importância apenas para o PT (SAMUELS, 2004b).

Voltemos agora à análise da Tabela 4. Após o posicionamento esquerda. direita, vemos que os brasileiros mais envolvidos em "participação não-eleitoral" apresentam uma probabilidade $15 \%$ maior de serem petistas. Entre os tipos de atividades que entraram na construção do índice de participação não-eleitoral estão a participação em sindicatos, em movimentos sociais e em movimentos de bairro. Os brasileiros que estão mais envolvidos do que a média em política eleitoral também apresentam maior probabilidade de serem petistas, assim como os mais escolarizados que também se interessam por política (conhecimento político). Relacionado a isso, vemos que os brasileiros que têm uma visão positiva da eficácia da participação em política - acham que sua participação pode fazer diferença têm maior probabilidade de se identificar com o PT. Esses resultados sobre participação política e o valor percebido da participação talvez não surpreendam, consideradas as ligações históricas do PT com movimentos sociais e sua ênfase no empoderamento das bases. Por fim, é mais provável que sejam petistas os brasileiros com opinião negativa sobre o governo de Fernando Henrique Cardoso. Este resultado também não apresenta surpresa, embora muitos estudiosos prefiram não associar fatores de curto prazo como "avaliação retrospectiva" com uma disposição psicológica, como a identificação partidária. Esta questão merece exame ulterior. 


\section{Conclusões}

Este trabalho tentou descobrir as bases do petismo. Os petistas diferem dos outros brasileiros em aspectos específicos: embora não se diferenciem substancialmente em termos de suas posições sobre políticas públicas ou seu apoio ou oposição ao clientelismo ou ao rouba-mas-faz, eles diferem no fato de que apresentam maior probabilidade de agir de modo diferente dos outros brasileiros. Especificamente, os petistas agem como se fossem contrários às formas tradicionais de política como o clientelismo e como se não apoiassem normas culturais brasileiras tradicionais, tais como a visão hierárquica da sociedade, ainda que não expressem atitudes extremamente diferentes sobre tais tópicos nas respostas a pesquisas. Os petistas não somente acreditam que a participação individual na política pode fazer diferença como tendem a agir com base nesta crença. Em contraste, os outros brasileiros não somente apresentam menor probabilidade de acreditar na participação política como também é menos provável que superem esse ceticismo engajando-se na política. Pode-se sugerir que o grau relativamente maior de escolaridade e de interesse pela política dos petistas, em comparação com os outros brasileiros, impulsiona essas crenças e ações políticas. A escolaridade talvez seja o "primeiro passo" na direção do desenvolvimento do petismo, enquanto o envolvimento político e social é uma manifestação de disposições psicológicas e se parece mais com um "último passo" para a afirmação de uma identificação com o partido.

Muitos se perguntam em que medida Lula é "maior" ou não do que o PT e, portanto, em que grau o petismo é uma função de uma ligação personalista ao líder mais importante do partido. Cremos que o personalismo molda o petismo em grau considerável, mas concluímos, em outro trabalho, que o personalismo é relativamente sem importância para o petismo, em comparação com sua importância para os outros partidos (SAMUELS, 2004b). Além disso, vale a pena repetir que não "precisamos" do personalismo para caracterizar adequadamente um petista, pois pode-se predizer com precisão quem será e quem não será petista, mesmo que os sentimentos dos brasileiros em relação a Lula não sejam incluídos ${ }^{9}$.

A importância para o petismo da popularidade de Lula tem implicações substanciais para o futuro do PT. Ele continua a ser o único líder petista que pode atrair um número de adeptos bem maior do que o partido. Quando ele deixar o

\footnotetext{
9 De qualquer modo, o motivo de a probabilidade predita de se identificar como petista aumentar tão substancialmente quando mudamos a avaliação de Lula de sua média para seu máximo é simplesmente devido ao alto grau de polarização em relação a Lula. Os petistas são obviamente bastante positivos com respeito a Lula e aqueles que não são petistas apresentam muito maior probabilidade de ter sentimentos ambivalentes ou negativos quanto a Lula. Há uma variação muito maior nas outras variáveis que estão, contudo, significativamente relacionadas ao petismo.
} 
palco, podemos prever não somente uma difícil sucessão na liderança, como também algum grau de problemas para o partido em termos de sua capacidade de reter seguidores e assim continuar crescendo eleitoralmente. O partido ainda não está inteiramente livre de sua conexão a um único líder político, como acontece nos EUA, por exemplo, onde os dois maiores partidos podem apresentar um candidato à presidência mais ou menos competitivo independentemente de quem possa ser esse candidato. É claro que, em relação aos outros partidos, a situação do PT é bastante boa. Ou seja, os outros partidos dependem ainda mais de personalidades políticas para seu nível mínimo de identificação partidária no eleitorado. Assim, uma questão fundamental para futura pesquisa é o grau em que o personalismo continuará a ser um elemento da identificação partidária com o PT.

Os resultados deste estudo têm implicações adicionais para o futuro do petismo. A ideologia de esquerda, que o próprio partido abandonou em larga medida, tem uma influência muito limitada na identificação dos brasileiros com o PT. O petismo também não mostra uma relação clara com políticas públicas determinadas, nem com classes sociais. Se o petismo fosse principalmente uma função dessas três variáveis (ideologia, políticas e classe), o crescimento do PT poderia ficar severamente limitado, pois muitos brasileiros possuem posturas ideológicas fracas, têm pouco conhecimento sobre políticas específicas e não têm uma consciência de classe clara.

Porém, o petismo parece atravessar, até certo ponto, classes e categorias sociais. A única "categoria social" associada ao petismo é o nível de escolaridade. Sugerimos que a educação esteja talvez associada a um desejo de obter conhecimento político que, por sua vez, está associado ao desejo de se envolver em política e com uma crença na ação individual. Em geral, os dados do ESEB indicam que a escolaridade anda junto com uma crença na eficácia da participação, bem como com um maior envolvimento em atividades sociais e políticas. Uma vez que esses fatores estão, por seu turno, associados ao petismo, isto sugere que maiores níveis de escolaridade no Brasil podem gerar apoio ao PT. No entanto, essa conclusão deixa ainda muita coisa para ser compreendida sobre as bases do petismo. Pesquisas futuras deverão buscar entender com mais clareza os contextos específicos em que o partidarismo do PT emerge entre os brasileiros de diferentes estratos sociais. 


\section{Bibliografia}

ALMEIDA, Alberto C. Comportamento eleitoral e ideologia. Trabalho apresentado na reunião de 2001 da ANPOCS, Caxambu, 2001.

A explicação do voto nas eleições presidenciais de 2002. Mimeo. Rio de Janeiro: Fundação Getúlio Vargas, 2004.

ALMEIDA, Jorge. Como vota o brasileiro ( $2^{\text {a }}$ ed). São Paulo: Editora Xamã, 1998.

BAIOCCHI, Gianpaolo (ed.). Radicals in Power: The Workers' Party and Experiments in Urban Democracy in Brazil. Londres: Zed Books, 2003.

BAKER, Andy. Free-Market Reform and Presidential Approval: The Politicization of Economic Policy Debates in Brazil. Dados 45 (1), p. 39-76, 2002.

CARREIRÃO, Yan de Souza. A decisão do voto nas eleições presidenciais brasileiras.

Florianópolis/Rio de Janeiro: Editora da UFSC/Editora FGV, 2002.

CARREIRÃO, Yan de Souza e KINZO, Maria d'Alva Gil. Os partidos políticos e a decisão de voto no Brasil. Trabalho apresentado na reunião da Associação Brasileira de Ciência Política. Niterói, 2002.

CRITERIUM Pesquisas de Opinião e Avaliação de Políticas Públicas. Expectativa Governo Lula. São Paulo: Criterium, 2003.

ERIKSON, Robert e GOLDTHORPE, John. The Constant Flux: A Study of Class Mobility in Industrial Societies. Oxford: Clarendon Press, 1992.

KECK, Margaret. The Workers' Party and Democratization in Brazil. New Haven: Yale University Press, 1992.

KING, Gary; TOMZ, Michael e WITTENBERG, Jason. Making the Most of Statistical Analyses: Improving Interpretation and Presentation. American Journal of Political Science, 44 (2), p. 347-61, 2000.

LIPSET, Seymour M. e ROKKAN, Stein. Party Systems and Voter Alignments. Nova York: Free Press, 1967.

MACAULAY, Fiona. The Purple in the Rainbow: Gender Politics in the PT. In: BAIOCCHI, Gianpaolo (ed.). Radicals in Power: The Workers' Party and Experiments in Urban Democracy in Brazil. Londres: Zed Books, 2003. 
MAINWARING, Scott. Rethinking Party Systems in the Third Wave of Democratization: the Case of Brazil. Stanford: Stanford University Press, 1999.

MAINWARING, Scott; MENEGUELLO, Rachel e POWER, Timothy. Partidos conservadores no Brasil contemporâneo. São Paulo: Paz e Terra, 2000.

MENEGUELLO, Rachel. PT: a formação de um partido, 1979-1982. São Paulo: Paz e Terra, 1989.

NYLEN, William. The Making of a Loyal Opposition: The Workers' Party (PT) and the Consolidation of Democracy in Brazil. In: KINGSTONE, Peter e POWER, Timothy J. (eds.). Democratic Brazil: Actors, Institutions, and Processes. p. 126-143. Pittsburgh: University of Pittsburgh Press, 2000.

RODRIGUES, Leôncio Martins. Partidos, ideologia e composição social: um estudo das bancadas partidárias na Câmara dos Deputados. São Paulo: Edusp, 2002.

SAMUELS, David. From Socialism to Social Democracy? Party Organization and the Evolution of the Brazilian Workers' Party. Comparative Political Studies, A sair, 2004a.

Sources of Mass Partisanship in Brazil. Inédito, University of Minnesota, 2004b.

SINGER, André. Esquerda e direita no eleitorado brasileiro. São Paulo: EdUSP/FAPESP, 1999.

TENDÊNCIAS - Encarte de Dados. Revista Opinião Pública, vol. 9, n² 2, p. 119-167, Outubro, 2003.

TOMZ, Michael; WITTENBERG, Jason e KING, Gary. CLARIFY: Software for Interpreting and Presenting Statistical Results. Version 2.1 Stanford University, University of Wisconsin, e Harvard University, 5 de janeiro, 2003. Disponível em http://gking.harvard.edu

VON METTENHEIM. The Brazilian Voter: Mass Politics in Democratic Transition (1974-1986). Pittsburgh: The University of Pittsburgh Press, 1995.

Tradução do original em inglês de Pedro Maia Soares. 